\title{
INFLUENCE OF FLOTATION BODIES ON THE POWER CHARACTERISTICS OF A FREE-STREAM WATER WHEEL
}

\author{
OLIVIER CLEYNEN, EMEEL KERIKOUS, STEFAN HOERNER \& DOMINIQUE THÉVENIN \\ Lehrstuhl für Strömungsmechanik und Strömungstechnik (ISUT/LSS), \\ Otto-von-Guericke-Universität Magdeburg, Germany
}

\begin{abstract}
The power characteristics of a small-scale floating water wheel model operated in a water channel are monitored when buoyant bodies designed according to volume constraints are added by its sides. It is shown that specific body angle configurations can reduce and even compensate for the power loss associated with the interference of the bodies' wake with the wheel. The bodies' Froude number and longitudinal position are also shown to influence power characteristics. This investigation of the influence of the buoyancy-providing installation on the power output of a free-stream water wheel paves the way for more precise optimization work using computational and experimental techniques.

Keywords: floating water wheels, free-stream hydropower, river flow, free surface.
\end{abstract}

\section{INTRODUCTION}

Hydraulic machines operating within the free stream of river or tidal flows may contribute to developing a decentralized electrical production network with near-zero ecological impact. In this context, research is carried out as part of the Fluss-Strom project with the aim to better understand the fluid flow mechanics within such machines [1]. Specifically, the mechanics of floating free-stream water wheels are currently investigated using computational fluid dynamics (CFD) and experimental techniques. Those machines are designed to operate within floating installations, which, due to the typically low power-to-weight ratio of water wheels, are required to provide large amounts of buoyancy. In the present work, an investigation of the influence of buoyant bodies on the power characteristics of a water wheel is carried out with a laboratory model.

To this effect, shaft power measurements are carried out on a small-scale water wheel model in a free-surface water channel. Two static solid bodies designed according to length and volume constraints are positioned symmetrically on the sides of the rotor, in a number of different positions. Power measurements at different characteristic rotor speeds then enable a quantification of the influence of installation rigs on the dynamics of free-stream water wheels.

\section{PROCEDURE}

A $30 \mathrm{~cm}$ diameter, $25 \mathrm{~cm}$-wide water wheel model is operated at the surface of a low-speed $\left(0,5 \mathrm{~m} \mathrm{~s}^{-1}\right)$, low-Froude $\left([\mathrm{Fr}]_{\infty}=0,3\right), 10 \mathrm{~m}$ long water channel (Fig. 1). The wheel is immersed at constant depth $d_{\text {wet }}=R / 3$; its shaft power output is measured with a Burster 8661-4500 torque $(M)$ and rotation speed $(\omega)$ sensor positioned between the wheel and a microcontroller-governed electrical generator. The incoming water velocity $U_{\infty}$ is recorded using a laser-Doppler (LDA) apparatus focused a point $5 \mathrm{~cm}$ deep and $100 \mathrm{~cm}$ upstream of the water wheel.

Two symmetrical solid bodies are then mounted on the sides of the water wheel rotor (Fig. 2). The bodies' geometry was chosen with constant cross-section along the vertical direction, for simplicity and modularity. To realistically account for the buoyancy role played in real-size installations, the overall ratio of immersed body volume to exposed wheel blade 


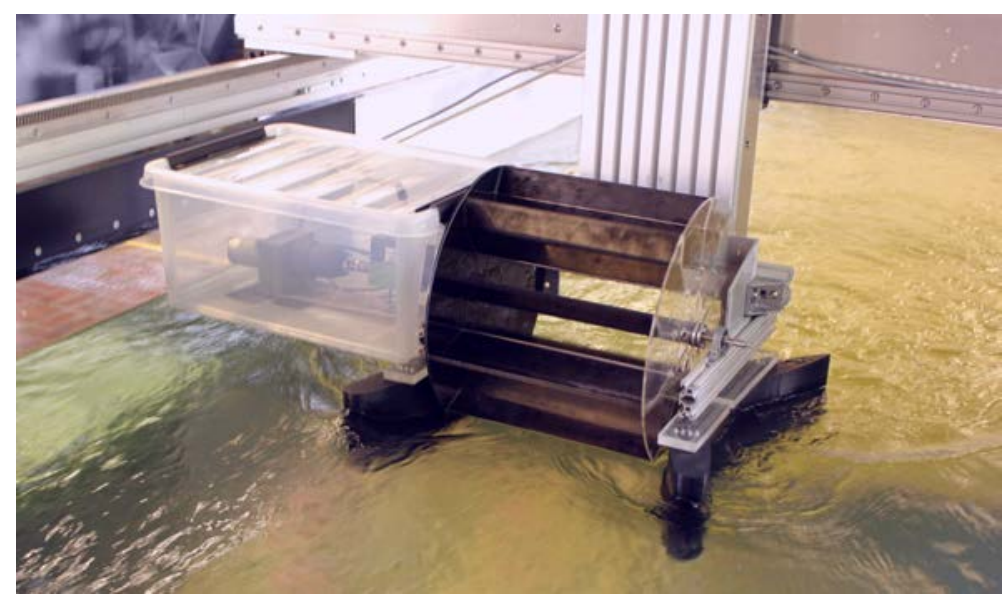

Figure 1: Water wheel operating in the water channel of the Otto-von-Guericke-Universität Magdeburg.

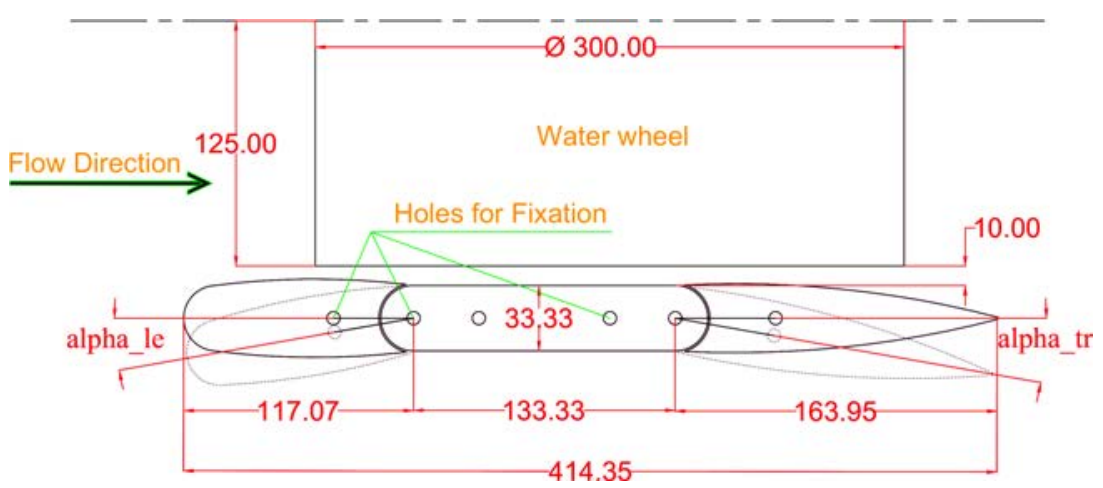

Figure 2: Plan view of a floating body installed around the water wheel, with the symmetry plane (for both wheel and buoyant body) shown on top. Dimensions are in millimeters.

area (approx. 4,5 m) was kept approximately equal to that of the Flotillenkraftwerk device developed by research project partner Sibau Genthin GmbH. The longitudinal distribution of volume, as well as the geometrical complexity, were also adjusted so as to reproduce a realistic geometry thus, the flat bottom duct surface and sharp angles featured in Batten et al. [2] and Weichbrodt et al. [3] are excluded from the present study. Since the device is mounted on a structure mounted onto the channel walls, the buoyancy force itself plays no role in this experiment.

The buoyant bodies' leading-edge and trailing-edge angles $\alpha_{\mathrm{le}}$ and $\alpha_{\mathrm{tr}}$ are independently adjustable between 0 and $30^{\circ}$; the bodies' longitudinal position can also be shifted relative to the wheel. Their lateral distance away from the wheel $(1 \mathrm{~cm})$ is maintained constant. At maximum $\alpha_{\text {tr }}$, the frontal area of bodies and wheel exposed to incoming water represents $12 \%$ of the channel cross-sectional area, a ratio deemed small enough that constriction effects can be safely neglected. 


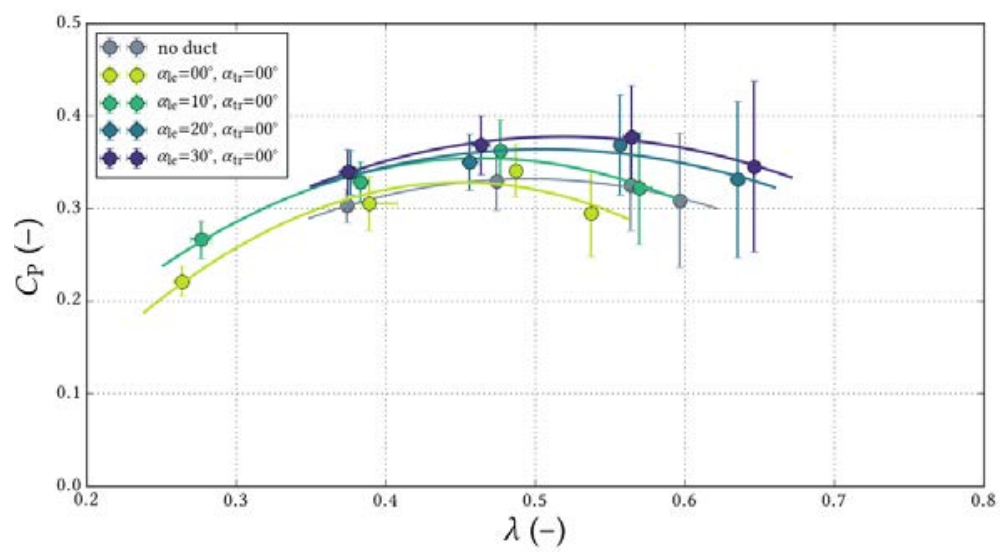

Figure 3: Power curves for different values of $\alpha_{\mathrm{le}}$ with straight trailing edge $\left(\alpha_{\mathrm{tr}}=0^{\circ}\right)$ at $V_{\infty} \approx 0,57 \mathrm{~m} \mathrm{~s}^{-1}$. A reference case without bodies shown in background (gray color). Mean deviations for each data point in this and the following figures are represented with horizontal and lateral whiskers.

For each tested configuration, the power output is measured for several rotor rotational speeds. For any one rotation speed, the instantaneous power coefficient $C_{\mathrm{P}} \equiv$ $\omega M /\left(\frac{1}{2} \rho S_{\mathrm{A}} U_{\infty}^{3}\right)$ is calculated and averaged over a period of $30 \mathrm{~s}$ or more. The mean deviation of the power coefficient, which accounts for sensor noise, generator-induced oscillations, uneven wheel hydraulic power delivery, as well as changes in water height and velocity, is also calculated. These points are plotted against the time-averaged tip speed ratio $\lambda \equiv \omega R / U_{\infty}$. Interpolation curves fit with a $2^{\text {nd }}$-degree (single-spline) polynomial are then drawn for each tested configuration. The interpolation curve obtained during a confirmation experiment deviated by an average $3,2 \%$ from the original.

In the present work, the buoyant bodies are seen as fixed-volume objects whose unavoidable presence interferes with the power output of an existing machine. Therefore, the reference area $S_{\mathrm{A}}$ used in the definition of the power coefficient does not account for frontal surface of the static bodies: the figures presented in the next section therefore quantify power density for a fixed-size rotor. The potential for buoyant bodies and ducts to increase a machine's global power characteristics is the subject of on-going theoretical [4] and numerical [5] work whose next results will be published in upcoming publications.

\section{RESULTS}

In the first experiments, power curves were acquired with and without the buoyant bodies in their straight position $\left(\alpha_{\mathrm{le}}=\alpha_{\mathrm{tr}}=0^{\circ}\right)$. Three additional positions for the leading edge angle were then investigated. The results are shown in Fig. 3.

In this figure, it can be seen that the addition of the bodies alongside the wheel has an immediate detrimental effect over the power output, particularly when the tip speed ratio exceeds 0,5 . Both this loss of power and the associated reduction of optimum tip speed ratio are recovered progressively as the body leading-edge angles are increased. Ultimately, when $\alpha_{\mathrm{tr}}=30^{\circ}$, an increase of $14 \%$ of the wheel-area-based power coefficient $C_{\mathrm{P}}$ is observed, together with a shift of the optimum tip speed ratio upwards by approximately $10 \%$.

The procedure is repeated with the body trailing-edge angle (varying $\alpha_{\mathrm{tr}}=0 \rightarrow 30^{\circ}$ while $\alpha_{\mathrm{le}}=0^{\circ}$ ), and the results are displayed in Fig. 4. While the increase of the trailing- 


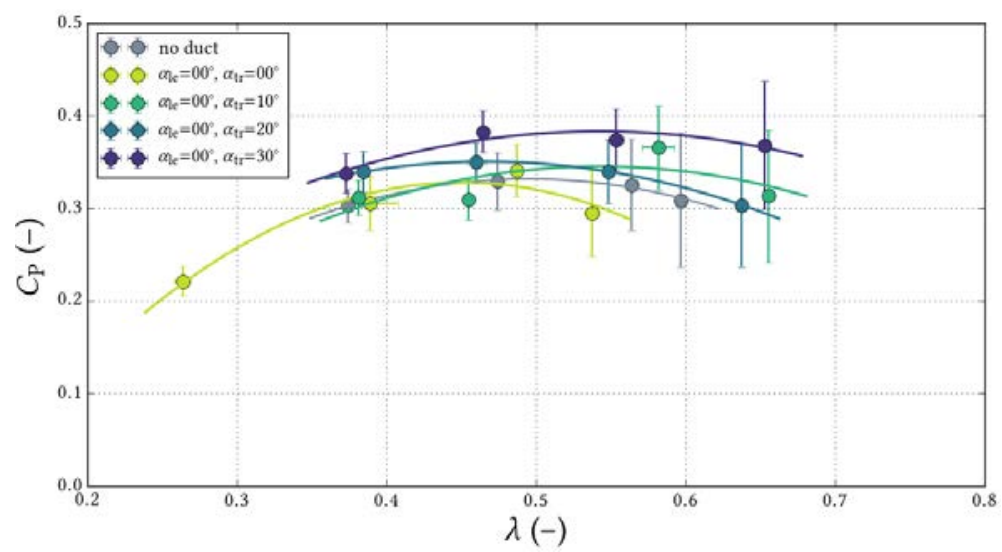

Figure 4: Power curves for different values of $\alpha_{\mathrm{tr}}$ with straight leading edge $\left(\alpha_{\mathrm{le}}=0^{\circ}\right)$. A reference case without bodies is shown in the background (gray color).

edge angle results in similar changes in the maximum power $\left(+15 \%\right.$ in $C_{\mathrm{P}}$ with approx. $+10 \%$ in $\lambda_{\text {opt. }}$ ), a significant power drop is observed at $\lambda>0,5$ for the case where $\alpha_{\text {tr }}=20^{\circ}$. An investigation of the flow properties (bow wave position and velocity in immediate vicinity of wheel) will be carried out in the future to relate these integral power curve characteristics to the physics of the flow in the machine.

The same experiment was carried out at higher flow speed in order to investigate the effect of the Froude number on the net power characteristics. The average inlet velocity $U_{\infty}$, av. was increased from 0,57 to $0,65 \mathrm{~m} \mathrm{~s}^{-1}$, resulting in body-length Froude number $[\mathrm{Fr}]_{\text {body }}$ increase from 0,29 to 0,33 . It was observed that increases in the average free-stream velocity, which are coupled with narrower bow waves, but also with lower water wheel hydraulic efficiencies, result in a shift of power coefficient curves towards the right (enabling sensibly higher tip speed ratios), without any significant change in the maximum attainable power coefficient.

A final set of experiments compares the power curves of different configurations with varying the longitudinal position of the buoyancy bodies. The effect of sliding the bodies downstream by a length equal to 1/3 times the wheel diameter can be read from Fig. 5 .

From Fig. 5, it can be seen that in both configurations tested, positioning the buoyant bodies further downstream relative to the water wheel resulted in slight increases in maximum achievable power (although these changes are of the order of magnitude of the recorded timewise oscillations in power delivery), and strongly reduced the power attainable at low speeds.

\section{CONCLUSIONS AND OUTLOOK}

Experiments conducted on a model water wheel in laboratory conditions, using timeaveraged mechanical power measurements, make it possible to describe quantitatively the interference of the flotation installation on the power output of a free-stream floating hydropower installation. Using a simplified geometry determined according to immersed volume constraints, the following trends could be observed:

- In its simplest configuration (straight flotation bodies), an immediate detrimental effect on the power characteristics is noticed, which can be recovered when either the leadingedge or trailing-edge angles is increased;

- The effect of the trailing-edge angle on the power output is non linear; 


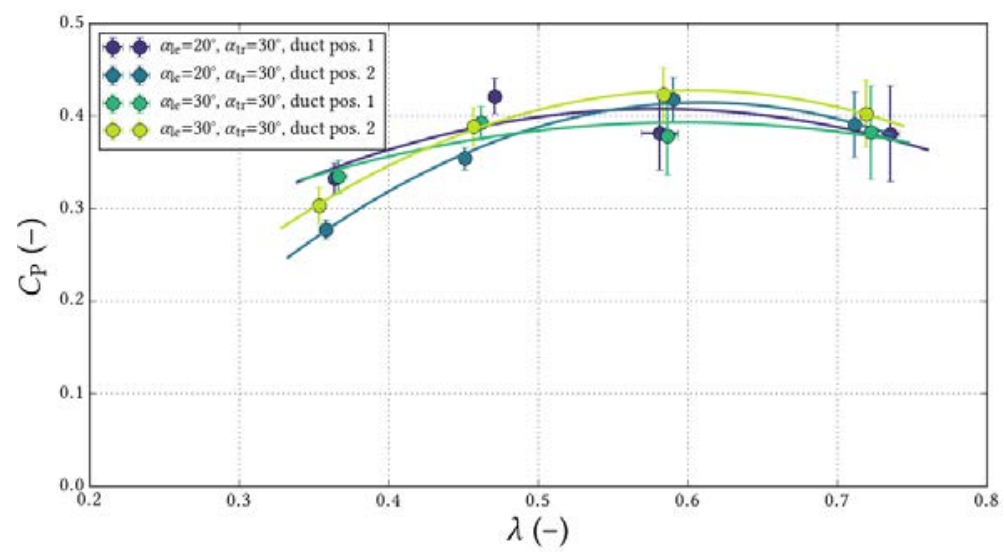

Figure 5: Power curves for two different body angle configuration, each at two different longitudinal positions. Dark curves correspond to $\alpha_{\mathrm{le}}=20^{\circ} \& \alpha_{\mathrm{tr}}=30^{\circ}$. The two lighter-colored curves correspond to cases where $\alpha_{\mathrm{le}}=\alpha_{\mathrm{tr}}=30^{\circ}$.

- A $10 \%$ increase in the body Froude number results in increased optimum rotation velocities, with unchanged power coefficient;

- Shifting the ducts longitudinally in the downstream direction results in decreased power output at low rotation speeds, and increased output at high rotation speeds.

Further work will now be carried with two general objectives:

1. Characterize the flow velocity and surface altitude close to the wheel. This, in particular, would help understand and control the bow wave pattern in which the water wheel operates in between the buoyancy bodies;

2. Improve measurement and control of the water surface level in the channel. With precise quantification of the immersed depth, incoming velocity and rotation speed occurring at every moment in time, a more precise evaluation of the power coefficient and much more effective noise filtering could be carried out, over lower measurement times.

Those developments would increase the precision of model water wheel measurements so as to provide reliable data by which to assess and validate CFDsimulations. Numerical investigations could then be used to map and optimize the power characteristics of water wheels in the context of their operation in low-ecological-impact, floating installations.

\section{ACKNOWLEDGEMENTS}

The authors are grateful for the financial support provided by the Fluss-Strom project financed by the Bundesministerium für Bildung und Forschung (German Federal Ministry of Education and Research) under the project number 1714. Mr. Emeel Kerikous would like to thank the Egyptian Government for their financial support during this research.

The assistance of Mr. Farooq Hussain in carrying out experiments, of Mr. Michael Haarmann (Firma CATLAB) in setting-up the model water wheel, and of Mr. Dirk Meinecke in rigging the power measurement system, are all very gratefully acknowledged. 
60 Computational and Experimental Methods in Multiphase and Complex Flow IX

\section{REFERENCES}

[1] Wachstumskern Fluss-Strom Plus, Grundlastfähige energiegewinnung durch ökologisch verträgliche flusswasserkraftanlagen.

[2] Batten, W. et al., Design and stability of a floating free stream energy converter. Proceedings of the Congress-International Association for Hydraulic Research (IAHR), p. 2372, 2011.

[3] Weichbrodt, F., Dimke, S., Hadler, J. \& Fröhle, P., Großmaßstäbliche modellversuche mit einem schwimmenden energiewandler. Dresdner Wasserbauliche Mitteilungen, pp. 291199, 2012.

[4] Cleynen, O., Hoerner, S. \& Thévenin, D., Characterization of hydraulic power in freestream installations. International Journal of Rotating Machinery, 2017, 2017.

[5] Cleynen, O., Hoerner, S. \& Thévenin, D., Performance mapping of ducted free-stream hydropower devices. Proceedings of the fourth IAHR Europe Congress, 2016. DOI: $10.1155 / 2017 / 9806278$. 